\title{
Session 8: IP Issues
}

Tuesday 8th November 2011. Moderator: Don Capra

[16.10-16.40]

'Centocor vs. Abbott: Are US Courts losing their affinity for broad antibody patent protection?'

Andrew T. Serafini

Fenwick and West LLP, Seattle, WA, USA

Abstract not provided.

[16.40-17.00]

'Biotech Patents: Genes, Antibodies and Andy Warhol'

Tom Gallagher

Kadmon Corporation, New York, NY, USA

Abstract not provided.

[17.00-17.20]

'Poker Face: Landscape of Antibody IP 2011'

James W. Larrick

Panorama Research Institute, Sunnyvale, CA, USA

Abstract not provided.
[17.20-17.40]

'The Antibody Patenting Debate: A tale of two cultures'

Averie Hason

Imclone Systems Inc., Bridgewater, NJ, USA

Abstract not provided.

[17.40-18.00]

'Expert witnesses/consultants in IP cases'

Matthew Pearson

Akin Gump, Philadelphia, PA, USA

Abstract not provided. 